\title{
UZBROJENIE Z CMENTARZYSKA KULTURY LUBOSZYCKIEJ W SADZARZEWICACH, POW. KROSNO ODRZAŃSKIE
}

SŁowa KLuCzowe: uzbrojenie; kultura luboszycka; cmentarzysko

KEYwORDs: weapons; Luboszyce culture; cemetery

\section{KRÓTKA HISTORIA BADAŃ I CHARAKTERYSTYKA STANOWISKA}

Cmentarzysko w Sadzarzewicach, pow. Krosno Odrzańskie (miejscowość nosiła przed II wojną światową nazwę Sadersdorf) należy do najważniejszych stanowisk z młodszego okresu przedrzymskiego i okresu wpływów rzymskich na obszarze Dolnych Łużyc ${ }^{1}$ Nekropolia zaliczona została przez prof. Grzegorza Domańskiego (1979) do wyodrębnionej przez niego w 1979 r. kultury luboszyckiej. Cmentarzysko w Sadzarzewicach tworzy razem m.in. z położonymi nieopodal stanowiskami w Grabicach i Luboszycach najstarszą fazę funkcjonowania tej jednostki taksonomicznej, a dolnołużycki kompleks osadniczy wspólnie

\footnotetext{
${ }^{1}$ Chcielibyśmy w tym miejscu gorąco podziękować Profesorowi Marianowi Głoskowi, promotorowi dysertacji Karola Demkowicza, z której pochodzi większość materiałów wykorzystanych w poniższym opracowaniu, a także Profesorowi Grzegorzowi Domańskiemu za poświęcenie swojego czasu na bezcenne konsultacje, dotyczące zawiłej problematyki kultury luboszyckiej. Niniejszy artykuł nie powstałby bez przeprowadzenia kwerendy w Muzeum Archeologicznym w Zielonej Górze z siedzibą w Świdnicy oraz w Muzeum Archeologicznym w Poznaniu. Chcielibyśmy podziękować w tym miejscu dyrekcjom tych placówek za udostępnienie zabytków i wyrażenie zgody na ich publikację. Nieoceniona okazała się również pomoc pracowników wymienionych instytucji przy wykonywaniu dokumentacji - winniśmy wdzięczność zwłaszcza mgr Arkadiuszowi Michalakowi oraz mgr Alicji Gałęzowskiej. Bardzo pomocne były również materiały z prywatnego archiwum Martina Jahna przechowywane w Instytucie Archeologii Uniwersytetu Warszawskiego. Za ich udostępnienie oraz wyczerpującą pomoc merytoryczną dziękujemy dr Bartoszowi Kontnemu.
} 
z nadodrzańskim uznawany jest za punkt wyjściowy dla późniejszej ekspansji całej kultury (Domański 1979: 103-107; 2010b: 240).

Mimo wielkiego znaczenia cmentarzyska dla pradziejów regionu stan jego opracowania jest niestety dalece niewystarczający. Stanowisko zostało przebadane w 1893 r. przez Hugo Jentscha, nauczyciela gimnazjalnego, pradziejowca z zamiłowania i prezesa Niederlausitzer Gesellschaft für Anthropologie und Altertumskunde w latach 1892-1916 (Domanski 1979: 10). Mimo, że badacz ten miał bogate doświadczenie terenowe, to trudna sytuacja na omawianej nekropolii najwyraźniej przerosła możliwości rodzącej się dopiero nowoczesnej archeologii. Cmentarzysko prawdopodobnie miało skomplikowaną stratygrafię oraz było zniszczona pracami leśnymi (o czym dowiadujemy się ze wzmianek w publikacji stanowiska). Dodatkowo nie można wykluczyć obecności cmentarzyska warstwowego, którego Hugo Jentsch nie rozpoznał. Wszystkie te okoliczności sprawiły, że wspomnianemu badaczowi, pozbawionego przecież dzisiejszej metodyki badań terenowych, nie udało się należycie wydzielić wielu pochówków (Domański 2010a: 14) i zostały one w jego publikacji opisane zbiorczo. Również wyposażenie licznych grobów ,jednostkowych” wzbudza poważne wątpliwości i trzeba liczyć się z możliwością, że stanowią one przemieszany materiał $\mathrm{z}$ wielu obiektów. Te podejrzenia potęguje dodatkowo skromna ilość dosyć schematycznych ilustracji oraz ogólnikowe i często wieloznaczne opisy zabytków tworzących zespoły. Z tego też powodu ponowna próba przyjrzenia się materiałowi z Sadzarzewic wymaga ryzykownych niekiedy interpretacji amatorskiej i archaicznej terminologii czy rysunków. Wyżej wymienione problemy sprawiły, że duża część materiału zabytkowego musi być traktowana jako luźna, a pochówki, które można uznać z dużym prawdopodobieństwem za zwarte, są bardzo nieliczne.

Jako punkt wyjściowy dla dalszych rozważań niech posłużą informacje zawarte w monografii opublikowanej w 1895 r. (Jentsch) - w przeważającej mierze jest to jedyny ślad po analizowanych zabytkach.

\section{Zabytki uzbrojenia $\mathrm{z}$ CMEnTarzyska w Sadzarzewicach w publikaCjach}

\section{MATERIALACH ARCHIWALNYCH}

Spośród broni zaczepnej znalezionej na cmentarzysku na pierwszym miejscu należy wymienić cztery miecze.

Pierwszym z nich jest znalezisko z grobu 21 (Jentsch 1895: 21-22; Archiwum...). Jest to najprawdopodobniej zwarty pochowek, bogato wyposażony w broń. Oprócz omawianego miecza zawierał on umbo oraz grot broni drzewco- 
wej bez zadziorów jak i grot z zadziorami. Hugo Jentsch datuje pochówek w oparciu o miecz na okres przedrzymski - egzemplarz ten miał według niego przejście trzpienia $\mathrm{w}$ głownię w kształcie zbliżonym do dzwonowatego z rozszerzeniem o formie prostokątnej, rozchylającym się następnie łukowato na zewnątrz. Martin Jahn, który oglądał zabytki z Sadzarzewic, twierdził z kolei, że miecz ma zwyczajne, łukowate przejście rękojeści w głownię, a pochówek ma metrykę zdecydowanie późnorzymską. Druga interpretacja wydaje się bardziej prawdopodobna z tej racji, że na obszarze Dolnych Łużyc jedyne osadnictwo poprzedzające horyzont $\mathrm{z}$ okresu rzymskiego wiązane jest $\mathrm{z}$ grupą gubińską kultury jastorfskiej, a pochówki tej jednostki niezwykle rzadko wyposażane były w broń. Ponadto, do grobu nr 21 miała należeć sprzączka z prostokątną ramą i skuwką, datowana na koniec okresu wczesnorzymskiego i początek późnorzymskiego. Obecność umba reprezentującego odmianę z tępym kolcem potwierdza taką metrykę, oczywiście przy założeniu, że nie mamy do czynienia z przemieszanym materiałem z okresu przedrzymskiego i rzymskiego. Miecz miał długość $70 \mathrm{~cm}$ i szerokość głowni 4,5 cm. Długość trzpienia wynosiła $11 \mathrm{~cm}$. Sztych miał formę ostrołukowata, a każdy z płazów zaopatrzony był w parę strudzin. Takie wymiary, przy założeniu kompletności znaleziska, sugeruja, ze mamy do czynienia z egzemplarzem typu Lachmirowice-Apa wg Marcina Biborskiego (2006: 185-193). Kombinacja zabytków o wymienionych cechach wskazuje na fazy B2b-C1a jako na odcinek, z którego pochodzi zespół.

Drugi egzemplarz odkryto (Jentsch: 42, Taf. III.9) w grobie nr 36 (ryc. 1.9). Jego długość całkowitą określono na $82 \mathrm{~cm}$ przy $6,5 \mathrm{~cm}$ maksymalnej szerokości głowni. Również i w tym przypadku sztych miał formę ostrołukowatą. Trzpień posiadał widoczne gołym okiem ślady zastosowania techniki dziweru kątowego przy wykuwaniu miecza, co stanowi mocną przesłankę do uznania go za rzymski import. Pochówek, z którego pochodził, był najlepiej wyposażony w broń spośród wszystkich grobów na stanowisku - zawierał on imacz, umbo z kolcem (najprawdopodobniej tępym), zdobiony grot włóczni, ostrogę oraz okucie końca pasa typu JII3 wg Klausa Raddatza (1957: 95). Korelacja chronologii ostatnich czterech wymienionych zabytków pozwala nam datować grób na fazę $\mathrm{Cla}^{2}$. W tym odcinku czasowym jedynym typem miecza, do którego można byłoby dopasować na podstawie wymiarów omawiany egzemplarz, to typ Buch-Podlodów wg Marcina Biborskiego (2006: 176-185).

\footnotetext{
${ }^{2}$ By uniknąć powtórzeń, analiza chronologiczna poszczególnych elementów zespołu zostanie przedstawiona dokładnie przy okazji omawiania grotu włóczni.
} 
Trzeci okaz (Jentsch: 59-60, Taf. III. 11-12) pochodzi z przemieszanych grobów 51-57 (ryc. 1.11-12). Dowiadujemy sie o nim tylko tyle, że mierzy on w całości $77 \mathrm{~cm}$, z czego $10 \mathrm{~cm}$ przypada na trzpień. Załączona w publikacji rycina sugeruje, że głownia zaopatrzona była w dwie strudziny i zakończona była ostrołukowatym sztychem.

W strudziny zaopatrzony był także miecz (Jentsch: 67-73, Taf. III.10) z przemieszanych grobów 58-59 (ryc. 1.10). Odkryty został on w niekompletnym stanie - brakowało partii sztychu. Długość trzpienia mierzyła $14 \mathrm{~cm}$, szerokość maksymalna głowni $-4,5 \mathrm{~cm}$.

Według Hugo Jentscha (1895: 42, 59, Taf. III.2) w grobie 36 (ryc. 1.2) i 51-57 miały zostać odkryte zawieszki pochwy miecza. Obecność tych zabytków wydaje się być zupełnie naturalna w zespołach zawierających miecze $\mathrm{i}$ w tych przypadkach najprawdopodobniej tworzyły one $\mathrm{z}$ omówioną bronią białą garnitur.

Pierwszy z wymienionych egzemplarzy na podstawie ryciny zaliczyć można do typu IIID wg Clausa von Carnap-Bornheima (1991: 43-46, Taf. 29.289295). Miał on ułamany w połowie kabłąk, nie sposób więc określić, do której odmiany wspomnianego typu zawieszek należał. Drugie znalezisko z kolei znane jest tylko z mało precyzyjnego opisu jako zbliżone do wymienionego w pierwszej kolejności. Zawieszki typu IIID, którym odpowiada typ VII wg Piotra Kaczanowskiego (1992: 41), datowane są na okres od B2b do C1.

Odmianą broni zaczepnej bardzo rozpowszechnioną w kulturze luboszyckiej (Domański 1979: 51) były topory. Znalezione zostały (Jentsch: 12, 56-57) w grobie nr 10 i przemieszanych pochówkach 48-50. Pierwszy pochówek z wymienionych zawierał topór o długości $13 \mathrm{~cm}$ i prześwicie osady o migdałowatym kształcie i długości 3,5 cm. Osada zaopatrzona była wąsy na dolnej jej krawędzi - występowanie toporów tego typu poświadczone jest w kulturze luboszyckiej począwszy od późnego odcinka $\mathrm{C} 1$.

W drugim $\mathrm{z}$ wymienionych grobów, tj. nr 48-50, znaleziono toporek o długości całkowitej 10,5 cm, o ostrzu szerokim na $5 \mathrm{~cm}$, a osadzie wysokiej na $1,8 \mathrm{~cm}$. Prześwit osady wynosił $1,8 \times 2,5 \mathrm{~cm}$.

Wśród grotów broni drzewcowej największą grupę stanowią egzemplarze bez zadziorów. Z grobu 21 (Jentsch: 22) pochodzi egzemplarz o długości całkowitej $16,5 \mathrm{~cm}$ i tulei mierzącej $6 \mathrm{~cm}$. Szerokość maksymalna zaopatrzonego w żeberko liścia wynosiła $3 \mathrm{~cm}$ przy grubości 1,2 cm. Tuleja wyróżniała się obecnością dwóch nitów mocujących drzewce.

W grobie $\mathrm{nr} 33$ znaleziono niewielki grot długości $11 \mathrm{~cm}$, z czego 4,5 cm przypadało na tuleję (Jentsch: 37-38). Element ten zaopatrzony był w otwór 
na nit, co mocno poświadcza, że nie mamy w tym przypadku do czynienia z grotem strzały. Szerokość liścia wynosiła $3 \mathrm{~cm}$, wyposażony był on w wydatne żeberko.

Z przemieszanych pochówków (Jentsch: 39) nr 34-35 pochodzi inny zabytek, długości $15 \mathrm{~cm}, \mathrm{z}$ 6-cio centymetrową tuleją i liściem szerokości 3,8 cm. Również i ten egzemplarz posiada żeberko, którego grubość sięga 1,6 cm - nie ma więc wątpliwości, że omawiany okaz jest egzemplarzem broni drzewcowej.

$\mathrm{Z}$ tego samego grobu znany jest grot (ryc. 1.4) o wyjatkowo długiej tulei $(9 \mathrm{~cm}) \mathrm{w}$ stosunku do długości całkowitej $(15 \mathrm{~cm})$. Liść miał szerokość $2 \mathrm{~cm}$ - tuleja grotu była nieznacznie tylko węższa (Jentsch: 39, Taf. III.4).

Najważniejsze znalezisko z omawianej kategorii (Jentsch: 42, Taf. III.1) odkryto w grobie 36 (ryc. $1.1 ; 2 ; 3$ ). Jest to grot zaopatrzony w pokrywający niemal całą powierzchnię liścia ornament rozchodzących się ukośnie od żeberka rzędów kresek. Zabytek ten zostanie omówiony dokładniej w dalszej części artykułu.

W przemieszanych grobach 58-59 (ryc. 1.7) znaleziono kolejny, zniszczony grot włóczni (Jentsch: 67, Taf. III.7). W chwili odkrycia zachowany fragment mierzył $12 \mathrm{~cm}$, a długość tulei wynosiła $6 \mathrm{~cm}$.

Na cmentarzysku w Sadzarzewicach wystąpiły również dwa groty z zadziorami, które potencjalnie mogły być elementami broni drzewcowej.

W grobie 21 znaleziono grot o długości całkowitej $12 \mathrm{~cm}$, z czego $9 \mathrm{~cm}$ przypadało na tuleję (Jentsch: 22). Długość zewnętrznych krawędzi zadziorów wynosiła $5 \mathrm{~cm}$, wewnętrznych $-2 \mathrm{~cm}$. Nie wiadomo, czy jest to rzeczywiście grot oszczepu, jak chce tego Martin Jahn (Archiwum), czy raczej grot strzały - gabaryty zabytku umożliwiają zarówno pierwszą, jak i drugą atrybucję. Brakuje niestety danych o grubości liścia, średnicy tulei, jej konstrukcji oraz sposobu mocowania do drzewca bądź promienia. Tylko na podstawie takich informacji możliwe byłoby dosyć pewne określenie przeznaczenia grotów o tak niewielkich rozmiarach ${ }^{3}$. Takie same wątpliwości wzbudza mocno uszkodzony korozją egzemplarz (Jentsch: 67-68, Taf. III.6) z przemieszanych grobów 58-59 (ryc. 1.6; 4). Również i ten okaz zostanie omówiony dokładnie w następnych akapitach tej pracy.

\footnotetext{
${ }^{3}$ Należy w tym miejscu zaznaczyć, że groty strzał z zadziorami na obszarze kultury luboszyckiej znalezione zostały jedynie na dwóch stanowiskach: Gohlis, Lkr. Meißen (Meyer 1971: 66-67, Abb. 37) i Golßen, Lkr. Dahme-Spreewald (Marschalleck 1944: Abb. 44). Są one wielką rzadkością w inwentarzu interesującej nas jednostki taksonomicznej (nie jest to popularna forma również w pozostałych częściach europejskiego Barbaricum w okresie rzymskim) co jest pewną poszlaką sugerująca, że okazy z Sadzarzewic interpretować należy raczej jako groty oszczepów.
} 
Bez większych wątpliwości jako groty strzał zakwalifikować należy egzemplarze z grobów 60 i 64 i przemieszanych pochówków 51-57 (Jentsch: 73, 78, $60)$. W ostatnim przypadku miało wystapić pięć sztuk grotów „pocisków miotanych" o długości całkowitej wynoszącej $14 \mathrm{~cm} \mathrm{z} \mathrm{czego} 5 \mathrm{~cm}$ przypadało na przedzielona, niezakutą tuleję. O egzemplarzu z grobu 60 wiemy tylko, że jest zbliżony do powyżej omówionych. Znalezisko z grobu 64 miało długość całkowitą $11,5 \mathrm{~cm}$, długość tulei $3 \mathrm{~cm}$ oraz szerokość liścia $1,5 \mathrm{~cm}$. Również i w tym przypadku tuleja nie była zakuta - egzemplarz miał być zbliżony do omówionych artefaktów z grobu 51-57.

Spośród uzbrojenia ochronnego, pochodzącego z cmentarzyska w Sadzarzewicach wymienić możemy cztery umba, zidentyfikowane jako zabytki z okresu wpływów rzymskich.

Pierwsze z nich pochodzić miało z grobu oznaczonego jako $\mathrm{nr} 21$. Hugo Jentsch określił jego wysokość na $18 \mathrm{~cm}$. Egzemplarz miał posiadać długi na $8 \mathrm{~cm}$ kolec, którego średnica minimalna wynosiła $1,2 \mathrm{~cm}$ i wzrastała do $1,6 \mathrm{~cm}$ przy końcu. Opierając się na pozostałych elementach wyposażenia pochówka, zwłaszcza na prostokątnej sprzączce ze skuwką, możemy go umieścić z dużą dozą pewności w ramach okresu rzymskiego. Idąc tym tokiem rozumowania, umbo trzeba zaliczyć do typu 7a wg Martina Jahna (1916; 175-176, Taf. III.7a), co odpowiada typom A2, B2, C2 i D2-3 wg Norberta Zielinga (1989: 34-40, 44-59, 62-69, 72-76). Należą one do najwcześniejszego horyzontu uzbrojenia w kulturze luboszyckiej, w którym możemy odnaleźć przemożny wpływ kultury przeworskiej ${ }^{4}$. Na tej podstawie można, w mojej ocenie, zawęzić chronologię tego okazu, jak i całego zespołu, na okres B2b-C1a.

Drugie umbo pochodzi z przemieszanych pochówków 34-35 (Jentsch: 3940). Niestety na temat jego formy nic nie wiadomo - autor publikacji wspomina jedynie, że w kryzie znajdowały się cztery otwory, spośród których jeden jeszcze zawierał nit.

Trzeci egzemplarz znaleziono w grobie nr 36 (Jentsch: 42). Autor wspomina, że zabytek posiadał trzy nity mocujące. Ponadto zwrócił uwagę na jego zły stan zachowania, oraz na obecność kolca (najprawdopodobniej tępego) długości $7 \mathrm{~cm}$.

Czwarty okaz z omawianego stanowiska (Jentsch: 68, Taf. III.8) pochodzić miał z grobów oznaczonych numerami 58-59 (ryc. 1.8). Zabytek miał średnicę $15 \mathrm{~cm}$, z kryzą szeroką na $3,5 \mathrm{~cm}$. W przypadku tego znaleziska dysponuje-

\footnotetext{
${ }^{4}$ Wspomnieć należy również o niewielkim udziale zabytków o cechach charakterystycznych dla kręgu nadłabskiego jak umbo z Rappic, pow. Słubice (Leube 1992: 315, 324, Taf. 9.1) czy imacz z Langewahl, Lkr. Oder-Spree (Dölle 1985).
} 
my rysunkiem, jest on jednak bardzo schematyczny. Sam autor nie rozstrzyga, czy mamy do czynienia z umbem półkulistym, kopulastym czy zakończonym kolcem - na taki stan rzeczy wpływ miał bardzo zły stan zachowania zabytku. Fakt ten, w połączeniu z niedostateczną szczegółowością publikacji, uniemożliwia jakiekolwiek sklasyfikowanie artefaktu.

Nekropolia dostarczyła również dwóch imaczy (Jentsch: 39, Taf. III.3, 42). Obydwa miały według autora opracowania stanowiska wystapić razem z przytoczonymi już powyżej umbami. Pierwszym z nich jest egzemplarz z przemieszanych grobów nr 34-35 (ryc. 1.3; 5). Był on zaopatrzony w ornament wypiłowywanych linii - zostanie on dokładniej opisany w następnej części niniejszego opracowania.

Drugi okaz pojawił się w grobie 36 . Wiadomo o nim jedynie tyle, że posiadał zdobienie.

Najliczniejszą kategorią uzbrojenia na cmentarzysku w Sadzarzewicach są elementy oporządzenia jeździeckiego w postaci ostróg. Wszystkie należały prawdopodobnie do odmiany kabłąkowej z zaczepami guzikowatymi. Jedynym okazem, który można precyzyjnie sklasyfikować dzięki zamieszczonej rycinie jest znalezisko z przemieszanych pochówków 58-59 (Jentsch: 69, fig. 25) Egzemplarz ten miał czworokątny w przekroju bodziec i wykonany został z brązu. Zaliczyć go należy do typu E6 wg Jerzego Ginalskiego (1991: 63), datowanego na fazę C1a. Identyfikacja pozostałych jest obarczona znacznym stopniem ryzyka bądź wręcz jest niemożliwa.

W tzw. grobie 25-32 znaleziono dwie ostrogi (Jentsch: 32-33). Jedna z nich, wykonana $\mathrm{z}$ brązu, miała mieć kabłąk rozszerzający się rombowato $\mathrm{w}$ jego środkowej części oraz bardzo masywny, pusty w środku bodziec. Cechy te - zwłaszcza pierwsza z wymienionych - wskazują na późnorzymską metrykę znaleziska (Godłowski 1977: 89; Ginalski 1991: 64). O drugim egzemplarzu, żelaznym, wiemy jedynie tyle, że miał wąski kabłąk.

Okaz z grobu 36 (Jentsch: 43) z Sadzarzewic, pow. Krosno Odrzańskie był pokaźnych rozmiarów, oraz posiadał ozdobiony dwoma rowkami, stożkowaty bodziec mocowany nitem do poszerzonego rombowato kabłąka. Cecha ta, jak już wspomniano, uznawana jest za charakterystyczną dla egzemplarzy późnorzymskich i pozwoli nam na pewniejsze datowanie zespołu.

Ostroga z grobu 38 (Jentsch: 45) wykonana została najprawdopodobniej z żelaza. Również i ona posiada rozszerzający się romboidalnie kabłąk.

\footnotetext{
${ }^{5}$ Przy okazji omawiania tego zabytku autor podaje informację, że na tym stanowisku znaleziono przypadkowo jeszcze jedną podobną brązową ostrogę, i trzy dalsze, wykonane z żelaza. Ponieważ odkrycia dokonała przypadkowo osoba nie zajmująca się archeologią (miejscowy leśniczy), a zabytki nie zachowały się, trudno traktować tę informację jako w pełni wiarygodną.
} 
Jej bodziec miał być zaopatrzony w grań biegnącą aż do kabłąka i przecinającą go poprzecznie. Cechy te wskazują, że mamy do czynienia z formą późnorzymską.

W grobie 44 (Jentsch: 51) wystąpiła para niewielkich ostróg o stożkowatym bodźcu. Nic więcej na ich temat niestety nie wiadomo.

Z przemieszanych grobów 48-50 (Jentsch: 57) miały pochodzić dwie pary egzemplarzy. Pierwsza para miała taśmowaty, rozszerzający się rombowato kabłąk oraz stożkowaty bodziec zdobiony dwoma rowkami. Na podstawie tego opisu można z pewnym prawdopodobieństwem przyporządkować te okazy do podgrupy F wg Jerzego Ginalskiego (1991: 64-67), której chronologia ogranicza się do fazy $\mathrm{C} 1$. Druga para również posiadała rombowato poszerzony kabłąk oraz przynitowany bodziec i wykonana była z żelaza.

W grobie 65 wystapiła żelazna ostroga, którą Hugo Jentsch określił jako podobną do egzemplarza z grobu $58-59$.

OdNALEZIONE I ZIDENTYFIKOWANE ZABYTKI UZBROJENIA Z CMENTARZYSKA w SAdZarzewicach

Materiały z cmentarzyska w Sadzarzewicach trafiły do założonego przez Hugo Jentscha muzeum w Gubinie. Prawie całe zbiory tej placówki zaginęły $\mathrm{w}$ czasie prowadzonych w tym mieście działań wojennych oraz w okresie anarchii, który nastąpił później. W trakcie przeprowadzonej przez autorów kwerendy muzealnej udało się odnaleźć niektóre z wymienionych zabytków.

Pierwszym z nich jest ornamentowany grot włóczni z grobu 36 (Jentsch: 42, Taf. III.1). W publikacji odnajdujemy informację, że posiadał on długość całkowitą wynoszącą $20,5 \mathrm{~cm}$ przy długości tulei $5,7 \mathrm{~cm}$. Otwór na nit umieszczony był w odległości $1,5 \mathrm{~cm}$ od krawędzi tulei. Liść zaopatrzony był w żeberko oraz w ornament kresek rozchodzących się ukośnymi rzędami od osi symetrii. Owych rzędów było 25 do 27 i składały się z 5 do 25 kresek.

Niemalże wszystkie te dane odpowiadały wymiarom egzemplarza (z miejscowości nieznanej) ze zbiorów Muzeum Archeologicznego w Zielonej Górze z siedzibą w Świdnicy. Skatalogowany jest on pod numerem inwentarza MZG 533:1958. Z dokumentacji Muzeum można dowiedzieć się jedynie, że został on pozyskany w ramach „rewindykacji zbiorów Muzeum w Gubinie”. Długość całkowita domniemanego grotu z Sadzarzewic wynosi 20,4 cm, przy długości liścia 14,9 cm i tulei $5,5 \mathrm{~cm}$. Szerokość maksymalna liścia wynosi $3,9 \mathrm{~cm}$, a jego grubość liczona w partii pozbawionej żeberka zamyka się w wartości 
0,4 cm. Prześwit tulei ma średnicę 1,7 cm. Odległość najdalej odsuniętego od krawędzi otworu na nit mocujący wynosi $1,3 \mathrm{~cm}$. Zabytek waży $96 \mathrm{~g}$.

Brzegi liścia są uszkodzone przez korozję, a jego powierzchnię częściowo nadal pokrywa patyna ogniowa. Na lepiej zachowanej stronie grotu można dopatrzeć się 25 rzędów kresek (na jedynej połowie liścia, której powierzchnia jest w większości pokryta patyną ogniowa). Maksymalna liczba kresek w jednym rzędzie wynosi 16 (licząc od osi liścia do krawędzi tnącej), nie wiadomo jednak, w jaki sposób ich liczba była liczona przez Hugo Jentscha. Ciekawą cechą ornamentu jest fakt, że tworzą go kreski wypukłe. Zostały one wykonane najprawdopodobniej trzymaną pod kątem puncą. Mimo wspomnianych ubytków korozyjnych krawędzi liścia, można stwierdzić z dużą dozą pewności, że te nie tworzyły linii prostych lecz były zagięte. Dzięki temu zabiegowi zarys grotu niedaleko wierzchołka był lekko taliowany. Taki kształt jest charakterystyczny dla egzemplarzy typu I wg Piotra Kaczanowskiego (1995: 11-14). Omawiany grot nie spełnia w sposób absolutny kryteriów dla tej grupy, ponieważ zaopatrzony jest $\mathrm{w}$ słabo wyodrębnione żeberko (w przeciwieństwie do typowych, ostro wyodrębnionych). Niemniej, nie jest to anomalia decydująca, a najważniejsze cechy typu I w jego 3 odmianie (Kaczanowski 1995: 12-13, tabl. IV.2-3) są zachowane. Groty tego rodzaju na obszarze kultury przeworskiej datowane są przez Piotra Kaczanowskiego na okres wczesnorzymski i fazę C1a okresu późnorzymskiego.

Widniejący na powyższym egzemplarzu ornament jest bardzo rzadki na terenie Barbaricum. Do najbliższych analogii należąznaleziska z kultury luboszyckiej z Sonnewalde, Lkr. Elbe-Elster (Grosse 1905: 367-369; Leube 1975: 127), tzw. grobu 33 z Wilhelmsaue, Hauptstadt Berlin (Kossina 1905: 382, fig. 12; SchachDörges: 1969: 130-131, Abb. 17) oraz zaliczany do kultury przeworskiej egzemplarz z miejscowości nieznanej z Dolnego Śląska (Archiwum). W przypadku pierwszego i trzeciego z wymienionych ornament składał się z wklęsłych kresek, w przypadku drugiego - z wklęsłych punktów wykonanych tłoczkiem. Egzemplarz z Wilhelmsaue należy do grobu o najprawdopodobniej przemieszanym wyposażeniu, lecz biorąc pod uwagę formę grotu i chronologię cmentarzyska (C1-C2) można go datować na odcinek C1a. Znalezisko z Sonnewalde wystapiło w grobie pozbawionym czułych datowników. Ponieważ jest zbliżony do typu II wg Piotra Kaczanowskiego (1995: 14-15, tab. V.3-5), należałoby go datować na okres B2b-C1a. Warto również wspomnieć, że pokrewny rodzaj zdobienia grotów można zaobserwować na znacznie większej liczbie okazów pochodzących w przeważającej mierze $\mathrm{z}$ kultury przeworskiej. Ich powierzchnie są równomiernie pokryte kreskami, które jednak nie tworzą ukośnych rzędów. 
Chronologia tych zabytków ogranicza się do fazy B2 (Kontny 2001: 81-83; 2008: 139-141).

Zbieżność wymiarów i detali rzadkiego przecież rodzaju ornamentu oraz fakt, że okaz został pozyskany z Gubina, wydają się być wystarczająco silnymi przesłankami, by uznać grot z grobu 36 z Sadzarzewic za tożsamy z zabytkiem z Muzeum Archeologicznego w Zielonej Górze. Jak wielokrotnie w niniejszym artykule wspominałem, grób nr 36 zawierał bogate wyposażenie, które umożliwiło jego precyzyjne datowanie. Najbardziej przydatne w tym zakresie okazała się ostroga oraz okucie końca pasa. Pierwsza z wymienionych posiadała rombowato poszerzony kabłąk, okucie z kolei zaliczyć można do typu JII3 wg Klausa Raddatza (1957: 95). Obydwa zabytki ustalają chronologię zespołu na fazę C1. W korelacji z przytoczoną powyżej wczesną metryką grotu, która w oparciu tak o morfologię jak i typ zdobienia zabytku, zamyka się w fazach B2-C1a, możemy $\mathrm{z}$ dużą dozą pewności zawęzić chronologie całego zespołu do fazy C1a.

Kolejny ocalały zabytek z Sadzarzewic znajduje się w zbiorach Muzeum Archeologicznego w Poznaniu (nr kat. 160a) i jest to grot z zadziorami (Jentsch: 67-68, Taf. III.6) z przemieszanego grobu 58-59 (ryc. 1.6; 4). Z publikacji Hugo Jentscha dowiadujemy się, że w chwili znalezienia grot miał długość $15 \mathrm{~cm}$, z czego $9 \mathrm{~cm}$ przypadało na tuleję. Zadziory zostały określone jako silnie wygięte na zewnątrz - jeden $\mathrm{z}$ nich, zachowany w całości miał długość $6,5 \mathrm{~cm}$. Wewnętrzna ich krawędź posiadała osobliwe, długie na $4 \mathrm{~cm}$ wycięcia. W obrębie jednego z nich dało się zauważyć ząbkowanie. Autor XIX-wiecznej publikacji zasugerował, że grot mógł wieńczyć harpun do połowu ryb. Taki unikalny kształt opisanego i narysowanego grotu skłaniał do dużej rezerwy w odniesieniu do obserwacji Hugo Jentscha tym bardziej, że jego rysunki nieraz okazywały się być obarczone mylącymi nadinterpretacjami. Konfrontacja powyższych danych z zachowanym zabytkiem pozwoliła odrzucić zastrzeżenia i pokazała, że grot rzeczywiście ma bardzo niecodzienną formę. Zadziory istotnie zaopatrzone są w wycięcia, a jeden z nich ma ząbkowaną wewnętrzną krawędź. Długość całkowita zachowanego zabytku wynosi dzisiaj jedynie $8,8 \mathrm{~cm}$, przy długości tulei $5,7 \mathrm{~cm}$. Maksymalna szerokość grotu to $5,1 \mathrm{~cm}$. Nieułamany zadzior mierzy $5,9 \mathrm{~cm}$ długości i $1,5 \mathrm{~cm}$ szerokości maksymalnej. Prześwit resztek tulei wynosi $0,8 \mathrm{~cm}$. Grubość liścia to $0,4 \mathrm{~cm}$, a masa zabytku wynosi $36 \mathrm{~g}$. Mniejsze wartości przytoczonych wymiarów w stosunku do opisanych przez Hugo Jentscha wynikają zapewne z postępującej korozji i zabiegów konserwatorskich, jakim został poddany od tamtego czasu. 
Nie ma pewności, jakiego rodzaju pocisku jest to grot. Niewielka średnica tulei wskazuje na grot strzały, jednak nie ulega wątpliwości, że pierwotnie element ten był znacznie dłuższy (co najmniej $3 \mathrm{~cm}$ opierając się na danych Hugo Jentscha), co automatycznie przekładało się na większy prześwit. Również brak szczeliny na tulei oraz znaczna pierwotna długość całkowita $(15 \mathrm{~cm}$ mimo znacznego uszkodzenia) sugeruje (choć nie przesądza!), że zabytek należy jednak traktować jako grot oszczepu. Jest to tym bardziej prawdopodobne, że w kulturze luboszyckiej groty strzał z zadziorami są bardzo rzadko spotykane - wystąiły jedynie na dwóch stanowiskach. Niemniej, na skutek fragmentarycznego stanu zachowania, nie sposób określić przeznaczenia zabytku w sposób nie budzący wątpliwości.

Okaz z Sadzarzewic jest niezwykle interesujący, ponieważ nie sposób wskazać innych grotów oszczepów lub strzał z analogicznymi wycięciami i zą̧bkowaniem krawędzi zadziorów datowanych na okres wpływów rzymskich i pochodzących z europejskiego Barbaricum. Najprawdopodobniej mamy tutaj do czynienia z lokalną odmianą.

Również w poznańskim Muzeum znajduje się trzeci istniejący zabytek z Sadzarzewic, czyli zdobione okucie imacza (Jentsch: 39, Taf. III.3) z przemieszanych grobów 34-35 (ryc. 1.3; 5). Z publikacji stanowiska dowiadujemy się, że miało ono $20 \mathrm{~cm}$ długości. Największa szerokość płytek na nity wynosiła $4,2 \mathrm{~cm}$, najmniejsza szerokość środkowej partii $-2 \mathrm{~cm}$. Zagięcie nitów mocujących okucie wskazywało, że grubość dranic tarczy w jej środku wynosiła $1,5 \mathrm{~cm}$.

Domniemany okucie imacza z Sadzarzewic figuruje obecnie pod numerem inwentarzowym 1945: 129 i katalogowym 1945: 505 jako znalezisko z miejscowości nieznanej. Niemniej, sugestia w odniesieniu do prawdopodobnego miejsca jego znalezienia została zaznaczona na karcie katalogowej, ponadto wiadomo, że trafiło ono do Muzeum Archeologicznego w Poznaniu z Gubina (Kostrzewski 1950: 167). Wymiary artefaktu są ściśle zbieżne z danymi przytoczonymi przez Hugo Jentscha: długość całkowita - 19,8 cm, długość zachowanej w całości płytki - 5,8 cm, szerokość maksymalna płytki 3,9 cm, szerokość uchwytu $-2 \mathrm{~cm}$, masa $-35 \mathrm{~g}$. Zabytek nosi ślady ornamentu tworzonego przez wypiłowane linie. Na rysunku z publikacji można zobaczyć parę wyżłobień wypiłowanych w centralnej części uchwytu, biegnących prostopadle do jego brzegów. Z każdej strony sąsiaduje z nimi para ukośnych linii - obydwie ustawione są do siebie zbieżnie. Na obu końcach uchwytu, przy płytkach na nity, widać również po parze prostopadłych nacięć. Mając w ręku oryginalny zabytek można jednak 
stwierdzić, że opisany rysunek jest zbyt daleko idącą rekonstrukcją, czy wręcz nadinterpretacją. Na skutek korozji środkowa partia ornamentu jest wyraźnie czytelna jedynie do około połowy szerokości uchwytu, ponadto jedna z ukośnych par jest niewidoczna. Nie ma również śladu po jednej z par nacięć przy płytkach do nitów. Bliższa obserwacja pozwoliła jednak stwierdzić, że wewnętrzne poprzeczne nacięcia były otoczone nie przez proste, skośne linie, lecz przez wzór kątowy, zbliżony to obróconej na bok litery „V”. Jest on bardzo podobny do rozpowszechnionego w całej Germanii motywu przylegających podstawami trójkątów, charakterystycznego dla okresu wczesnorzymskiego. Najczęściej można go spotkać na egzemplarzach z profilowanymi płytkami do nitów (Jahn 1916: 187-191, Abb. 204-205, 207, 209-211, 216, 222; Zieling 1989: 307-308, Abb. 11). Niemniej występuje on również młodszych typologicznie okazach - wskazać tutaj można jako przykłady imacz z wyodrębnionymi płytkami z Szymiszowa, pow. Strzelce Opolskie (Archiwum) czy z grobu 169 z Krupic, pow. Siemiatycze (Jaskanis 2005: 45, Taf. XLVII). Okucie imacza z Sadzarzewic należy zaliczyć do typu S1 wg Norberta Zielinga (1989: 209-213, Taf. 28.1-2). Okazy tej grupy $\mathrm{z}$ jedną parą nitów są datowane w kulturze przeworskiej na fazę $\mathrm{C} 1$.

\section{Podsumowanie}

Ogółem na cmentarzysku w Sadzarzewicach znaleziono 4 miecze, 2 zawieszki pochew mieczowych, 2 topory, 6 grotów broni drzewcowej bez zadziorów, 2 groty z zadziorami, 7 grotów strzał, 4 umba, 2 okucia imaczy i 12 ostróg. Daje to liczbę 41 elementów uzbrojenia na ok. 68 grobów. Jest to odsetek wyjątkowo wysoki wśród cmentarzysk kultury luboszyckiej, choć pamiętać trzeba, że większość uzbrojenia pochodzi z niewielkiej grupy (według Hugo Jentscha chodzi o 4 pochówki) bogato wyposażonych grobów. W takiej „militaryzacji” inwentarza należy jednoznacznie widzieć przejaw silnych wpływów kultury przeworskiej. Innym przejawem kontaktów ludności kultury luboszyckiej z sąsiadami ze wschodu jest sposób zdobienia grotu z grobu 36. Mimo niezaprzeczalnego podobieństwa do stosunkowo licznych grotów z ornamentem ściegowym z kultury przeworskiej, nie jest on identyczny ${ }^{6}$. Mamy tutaj najprawdopodobniej do czynienia z pewną modyfikacją starszego wzoru rozpowszechnionego u wschodnich sąsiadów. Groty zdobione tłoczonymi kreseczkami na całej powierzchni datowane są w kulturze przeworskiej na okres wczesnorzymski,

\footnotetext{
${ }^{6} \mathrm{Z}$ obszaru kultury przeworskiej znany jest tylko jeden grot $\mathrm{z}$ analogicznym zdobieniem do znaleziska z Sadzarzewic - grot z miejscowości nieznanej z Dolnego Śląska (Archiwum).
} 
podczas gdy egzemplarze luboszyckie pochodzą z okresu B2b-C1a ${ }^{7}$. Obserwacje te nie są w żadnym wypadku zaskakujące, bowiem udział tej jednostki taksonomicznej w kształtowaniu się, a później rozwoju kultury luboszyckiej jest niezaprzeczalny.

Cmentarzysko w Sadzarzewicach użytkowane było w okresie B2b-C2 i uzbrojenie na nim znalezione dobrze mieści się w tym przedziale czasowym. Warto zauważyć, że znaczna część broni, którą dało się w mniej lub bardziej precyzyjny sposób sklasyfikować, pochodzi najpóźniej z fazy C1. Niektóre zabytki, takie jak np. znaleziska z grobu 21 czy niezidentyfikowane ostrogi kabłąkowe moga pochodzić nawet $\mathrm{z}$ fazy $\mathrm{B} 2 \mathrm{~b}$, choć żadna przesłanka nie przemawia zdecydowanie za taką chronologią tych znalezisk. Na terenie całej kultury luboszyckiej nie odkryto żadnego grobu z uzbrojeniem, który można byłoby datować precyzyjnie na fazę $\mathrm{B} 2 \mathrm{~b}^{8}$, niemniej w przypadku tak wczesnego i ważnego stanowiska jakim są Sadzarzewice, nie można wykluczyć wczesnorzymskiej metryki któregoś $\mathrm{z}$ wymienionych egzemplarzy.

Warto zwrócić uwagę na dwie ostrogi wykonane z brązu. Jest to rzadko spotykany materiał $\mathrm{w}$ wyrobach tego rodzaju w kulturze przeworskiej, a charakterystyczny dla znalezisk z kultury wielbarskiej.

Zastanawiająca jest też mała liczba znalezionych toporów w stosunku do ilości grobów. Spowodowane było to zapewne, między innymi, dosyć wczesnym końcem funkcjonowania cmentarzyska - w czasie, gdy ten rodzaj uzbrojenia osiągał szczyt popularności w kulturze luboszyckiej, tj. w fazie $\mathrm{C} 2$, na cmentarzysku przestawano grzebać.

Spośród 41 znalezisk uzbrojenia z Sadzarzewic do naszych czasów przetrwały 3. Trudno mieć nadzieję, że uda się jeszcze odnaleźć wszystkie brakujące zabytki, niemniej szansa na chociaż minimalne polepszenie powyższego stanu dzięki dalszym poszukiwaniom w zbiorach muzealnych Polski i Niemiec nadal jest duża.

mgr Agata Andrzejewska

Uniwersytet Łódzki

Wydział Filozoficzno-Historyczny

Katedra Historii Sztuki

ul. Uniwersytecka 3

90-137 Łódź

\author{
dr Karol Demkowicz \\ Uniwersytet Łódzki \\ Wydział Studiów Międzynarodowych i Politologii \\ Zakład Studiów Latynoamerykańskich i Porównawczych \\ ul. Składowa $41 / 43$ \\ 90-127 Łódź
}

\footnotetext{
${ }^{7}$ Wcześniejsze datowanie $\mathrm{w}$ ramach tego odcinka jest mało prawdopodobne biorąc pod uwagę brak w kulturze luboszyckiej zabytków uzbrojenia o chronologii ustalonej w sposób pewny na koniec fazy B2.

8 Najwcześniejsze pochówki zawierają wyposażenie datowane zarówno na fazę B2b jak i C1a.
} 


\section{Bibliografia}

Źródła

Archiwum M. Jahna, Instytut Archeologii Uniwersytetu Warszawskiego.

Opracowania

Biborski M., Ilkjaer J. (2006), Illerup Ådal. Die Schwerter. Textband, „Jutland Archeological Society Publications", t. 25.11, Aarhus.

Carnap-Bornheim C. V. (1991), Die Schwertriemenbügel aus dem Vimose (Fünen), „Kleine Schriften aus dem vorgeschichtlichen Seminar aus dem PhillipsUniversität Marburg”, t. 38, Marburg.

Domański G. (1979), Kultura luboszycka między Łabq a Odrq w II-IV wieku, Ossolineum, Wrocław.

Domański G. (1994), Genetyczne i sqsiedzkie zwiqzki kultury luboszyckiej z kultura przeworska, [w:] Kultura przeworska, t. 1, red. J. Gurba, A. Kokowski, Lublin, s. 363-372.

Domański G. (2010a), Dorzecze dolnej Nysy Łużyckiej u schytku starożytności, Wydawnictwo Instytutu Archeologii i Etnologii PAN Oddział we Wrocławiu, Wrocław.

Domański G. (2010b), Zróżnicowanie obrzqdku pogrzebowego kultury luboszyckiej, [w:] Terra Barbarica. Studia ofiarowane Magdalenie Maczyńskiej w 65. Rocznice urodzin, red. A. Urbaniak, R. Prochowicz, I. Jakubczyk, M. Levada, J. Schuster, Monumenta Archaeologica Barbarica, Series Gemina, t. II, Instytut Archeologii Uniwersytetu Łódzkiego, Fundacja MAB, Łódź-Warszawa, s. 239-250.

Dölle H. J. (1985), Ein Kriegergrab der römischen Kaiserzeit aus Langewahl, Ortsteil Streitberg, Kreis Fürstenwalde (Spree), „Beiträge und Mitteilungen der Museum für Deutsche Geschichte Berlin”, t. 11, s. 31-35.

Ginalski J. (1991), Ostrogi kabłakowe kultury przeworskiej. Klasyfikacja typologiczna, „Przegląd Archeologiczny”, t. 38, s. 53-84.

Godłowski K. (1977), Materiały do poznania kultury przeworskiej na Gónym Ślasku, część II, „Materiały Starożytne i Wczesnośredniowieczne”, t. 4, s. 7-237.

Grosse H. (1905), Grabfund von Sonnewalde im Kreise Luckau, „Zeitschrift für Ethnologie", t. 37, s. 367-369.

Jahn M. (1916), Die Bewaffnung der Germanen in der älteren Eisenzeit, etwa von $700 v$.

Chr. bis 200 n. Chr., Mannus-Bibliothek 16, Würzburg.

Jaskanis J. (2005), Krupice. Ein Gräberfeld der Przeworsk- und Wielbar-Kultur in Ostpolen, Monumenta Archeologica Barbarica, t. 10, Fundacja MAB, Kraków. 
Jentsch H. (1895), Das Gräberfeld bei Sadersdorf, Kr. Guben, und ändere Niederlausitzer Fundstellen der La-Téne und provinzialrömischen Zeit, „Niederlausitzer Mitteilungen", t. 4, s. 1-143.

Kaczanowski P. (1992), Importy broni rzymskiej na obszarze europejskiego Barbaricum, Wydawnictwo Uniwersytetu Jagiellońskiego, Kraków.

Kaczanowski P. (1995), Klasyfikacja grotów broni drzewcowej kultury przeworskiej z okresu rzymskiego, Varia, t. 342, Uniwersytet Jagielloński, Kraków.

Kontny B. (2001), Uzbrojenie kultury przeworskiej z okresu wptywów rzymskich odkryte w 1884 roku w miejscowości Ścinawa-Jeżów (Georgensdorf), ,Silesia Antiqua”, t. 42, s. 77-95.

Kontny B. (2008) Dawna technika na nowo odkryta - uwagi na marginesie znaleziska grotu z Łodzi-Łagiewnik, ,Silesia Antiqua”, t. 44, s. 135-169.

Kossina G. (1905), Über verzierte Eisenlanzenspitzen als Kennezeichen der Ostgermanen, „Zeitschrift für Ethnologie”, t. 37, s. 369-407.

Kostrzewski B. (1950), Wykaz nabytków Muzeum Archeologicznego w latach 1945-1949, „Fontes Praehistorici”, t. 1, s. 164-214.

Leube A. (1975), Die römische Kaiserzeit im Oder-Spree-Gebiet, Veröffentlichungen des Museums für Ur- und Frühgeschichte Potsdam, t. 9, Berlin.

Leube A. (1992), Das germanische Gräberfeld von Rapice (früher Rampitz, Kr. Weststernberg) bei Zielona Góra. Kulturgeschichtliche Betrachtungen zum mittleren Odergebiet vom 1. Jahrh. v. Chr. bis zum 4 Jahrh. n. Chr., „Acta Praehistorica et Archaeologica”, t. 24, s. 301-337.

Marschalleck K. H. (1944), Urgeschichte des Kreises Luckau (Nieder-Lausitz), Verlag Brüke, Kirchhain N.-L.

Meyer E. (1971), Die germanischen Bodenfunde der spätrömischen Kaiserzeit und der frühen Völkerwanderungszeit in Sachsen, I. Katalog, „Arbeits- und Forschungsberichte zur sächsische Bodendenkmalpflege”, t. 9, Berlin.

Raddatz K. (1957), Der Thorsberger Moorfund. Gürtelteile und Körperschmuck, Wachholtz, Neumünster.

Schach-Dörges H. (1969), Das jungkaiserzeitliche Gräberfeld von Wilhelmsaue in Brandenburg, „Berliner Beiträge zur Vor- und Frühgeschichte”, t. 13, Berlin.

Zieling N. (1989), Studien zu germanischen Schilden der Spätlatene- und der römischen Kaiserzeit im freien Germanien, „Bulletin of Archeological Research International Series", t. 505, Oxford. 
SUMMARY

\section{ARMAMENT FROM THE CEMETERY OF THE LUBOSZYCE CULTURE IN SADZARZEWICE, POW. KROSNO ODRZAŃSKIE}

The cemetery in Sadzarzewice (former Sadersdorf) is one of the most important archaeological sites in Lower Lusatia and it dates back to the pre-Roman and Roman iron ages. It was included into the Luboszyce culture by Grzegorz Domański in his work from 1979. Along with two other cemeteries, located nearby in Grabice and Luboszyce, the Sadzarzewice complex constitutes the oldest chronological horizon of this taxonomic group, and the region is regarded as the starting point of its later expansion. Despite the site's great significance for the prehistory studies of the Oder basin, its state of study is far from satisfactory. This is mostly due to the fact it was discovered and explored at the end of the XIX ${ }^{\text {th }}$ century, that is in the time archaeological methods were still in development. Further complication was caused by the history of the region - nearly all of the artifacts were lost during WWII, and as an effect, the cemetery's inventory is known only from a publication dating back to 1895 . Nevertheless, during my research for my dissertation on the armament of the Luboszyce culture, I managed to identify a couple of those lost finds. This small group consisted of an ornamented spearhead, an untypical javelin- or arrowhead, and a shield grip. The total number of Roman iron age weapon and equestrian equipment finds from the cemetery is $41-4$ swords, 2 sword scabbard belt loops, 2 axes, 6 spearheads, 2 javelin heads, 7 arrowheads, 4 shield bosses, 2 shield grips and 12 spurs. The artifacts from Sadzarzewice fit into the phase B2b-C2 (late 2nd-3rd cent. A.D.) range. Those weapons that were possible to date with considerable precision can be situated within the phase $\mathrm{C} 1$, some even can be as old as B2b, although there is no certain evidence of such early chronology. Another notable feature of the Sadzarzewice artifacts is the evidence of various interregional influences - either from the West (the Elbian circle) and East (the Wielbark and Przeworsk cultures) which phenomenon, although characteristic for the Luboszyce culture in general, is best observed in the early stages of this unit's development. 


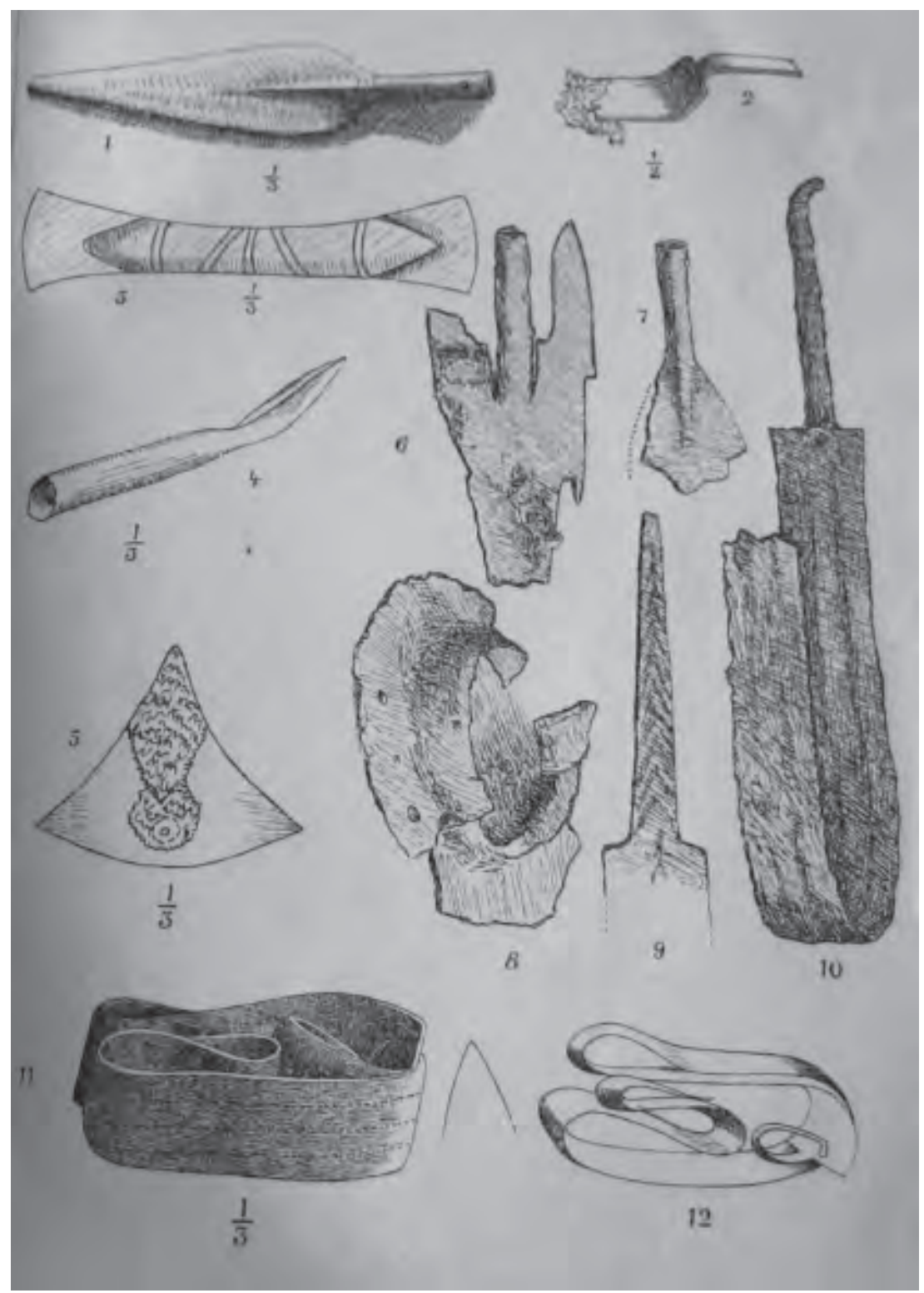

Ryc. 1. Przedstawienia uzbrojenia z cmentarzyska w Sadzarzewicach (Źródło: Jentsch 1895: Taf. III) 

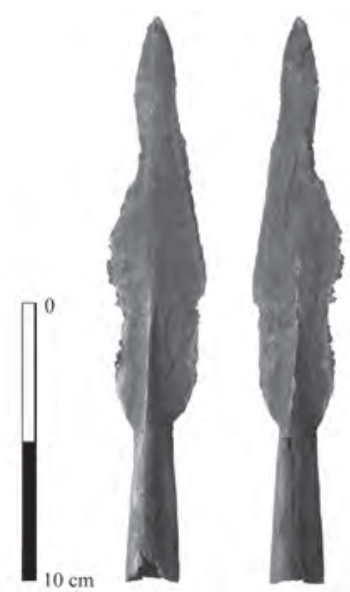

Ryc. 2. Grot włóczni z Muzeum Archeologicznego w Zielonej Górze, nr inw. MZG 533:1958 zidentyfikowany jako zabytek z grobu 36 z Sadzarzewic (Fot. A. Andrzejewska)

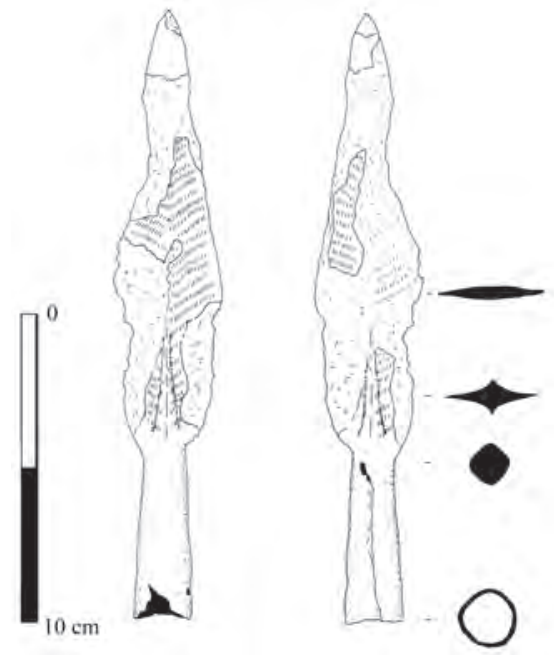

Ryc. 3. Grot włóczni z Muzeum Archeologicznego w Zielonej Górze, nr inw. MZG 533:1958 zidentyfikowany jako zabytek z grobu 36 z Sadzarzewic (Rys. A. Andrzejewska).
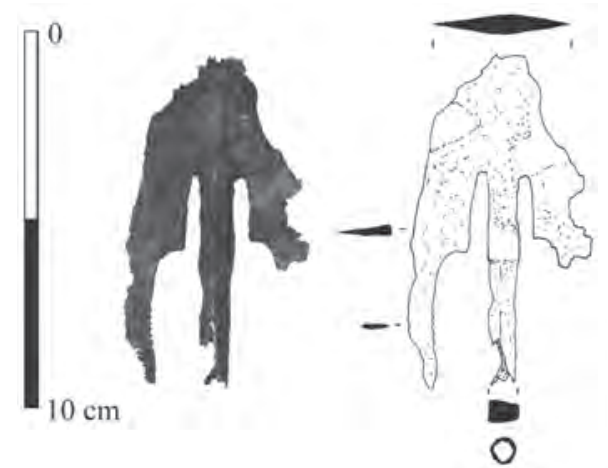

Ryc. 4. Grot z zadziorami z tzw. grobu 58-59 z Sadzarzewic ze zbiorów Muzeum Archeologicznego w Poznaniu, nr kat. 160a (Fot. i rys. A. Andrzejewska)
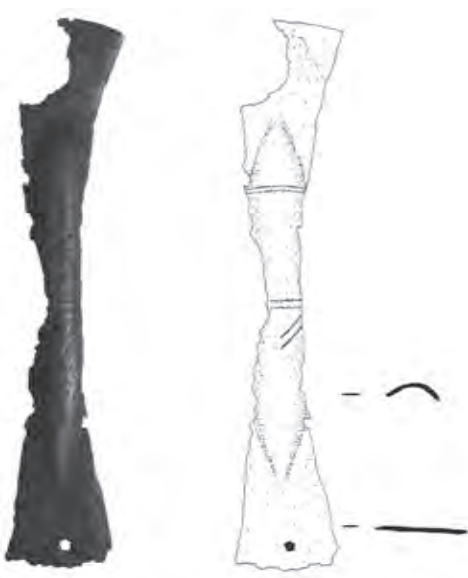

Ryc. 5. Imacz z miejscowości nieznanej ze zbiorów Muzeum Archeologicznego w Poznaniu. Zidentyfikowany jako znalezisko z tzw. grobu 34-35

(Fot. i rys. A. Andrzejewska) 